\title{
Review
}

\section{Quality of Life for End-Stage Renal Disease (ESRD) Patients Undergoing Peritoneal Dialysis (PD) Therapy: A Literature Review}

\author{
M. Hanif Prasetya 'Adhi', Yanny Trisyani², Etika Emaliyawati \\ ${ }^{1,2,3}$ Faculty of Nursing, Universitas Padjadjaran
}

\section{ARTICLE INFO \\ Article history: \\ Received 28-11-2019 \\ Received in revised from 19-12-2019 \\ Accepted 19-12-2019}

\section{Keyword:}

ESRD,

Peritoneal Dialysis, Quality of Life.

Other information:

Corresponding Email:

hanif18004@mail. unpad.ac.id

\begin{abstract}
Introduction: ESRD is an end-stage diagnosis which requires kidney replacement therapy such peritoneal dialysis (PD. The world's population and the prevalence of end-stage kidney disease continues to grow, patients are increasingly faced with the decision to start kidney replacement therapy. This review literature aims to analyze CAPD therapy in ESRD patients.

Methods: Investigations are limited to electronic databases such as Pubmed, Proquest, and Google Scholar, through the keywords of "ESRD", "CAPD", "Peritoneal Dialysis", "Quality of Life" compiled based on the MeSH Database from NCBI. The articles are reviewed through PRISMA and are analyzed by content analysis.

Results: 15 quantitative study, 7 qualitative study, 2 case reports, and 1 mixed method. Finding of this study was indicated that PD has contributed to strength, physicality, vitality, and pain-free. PD is linked with lower symptoms of depression and anxiety than HD. PD provides independence to lifestyle, self-efficacy, freedom of activity, flexibility, and a normal life, financially better and free to travel.

Conclusion: PD is proven to provide a better quality of life. Thus, it is important to develop PD therapy in ESRD patients who require long-term therapy.
\end{abstract}





\section{Introduction}

ESRD is an end stage diagnosis which requires kidney replacement therapy or kidney transplantation (Arora, 2015). The world's population continues to grow and the prevalence between chronic kidney disease (CKD) and endstage kidney disease (ESRD) is increasing, patients are increasingly faced with the decision to start kidney replacement therapy (RRT) in elderly patients (Jassal et al, 2007; Goh \& Griva, 2018). The recent incidence rate of dialysis patients reflects this situation, between 113 to 221 per million cases between the ages of 45 to 63 years, around 110 to 610 per million cases between the ages of 65 to 74 years and 99 to 984 cases per million people aged over 75 years (Stel et al, 2009).

Home Hemodialysis (HHD) was selected by $2 \%$ of the patients, Peritoneal Dialysis (PD) by $8 \%$ and at the dialysis center by $42 \%$ (UK Renal Registry, 2011). In America, the most recent estimation presented that only $8.4 \%$ of patients with ESRD currently use PD modalities (Heaf, 2004; United States Renal Data System (USRDS), 2003). There were an estimated 100,000 patients with ESRD at the Mexican Kidney Foundation. South Africa obtained a higher proportion of PD patients from the patients who received dialysis treatment, $80 \%$ used CAPD, $19 \%$ used HD and $1 \%$ used APD (Fundacion Mexiana del Rinon, 2007). According to the recent registration data, $71.8 \%$ of patients underwent renal replacement therapy by HD and $13.5 \%$ took PD (Tannor et al, 2017).

ESRD patients are required to adjust their psychology to their current illness, such as receiving life-threatening diagnoses and the need for lifelong care, learning dialysis techniques, integrating treatment into their life, overcoming treatment failure, and its complications (Cukor, 2007). The patient must also do and decide to initiate dialysis immediately. Most of medical personnel believe that patients have free authority to choose modality therapy (PD or HD) and practitioners are lack of the use of $\mathrm{PD}$ as a modality in ESRD patients (Dimkovic \& Oreopoulos, 2008).
In Indonesia, it was estimated that there were 100 cases per million population or around 20,000 new CKD cases in a year. Based on IRR (2015), the number of CKD in 2017 reached 30,831 new patients undergoing HD therapy, with active patients of 77,892. In 2017, active patients increased sharply which indicated that more patients could undergo longer hemodialysis. Whereas, patients with CAPD therapy in 2014 were 1,423, and in 2015 increased to 1,674 patients. It was only $3 \%$ of CAPD patients of all new patients in 2015. This finding is considered small since there are still many hemodialysis patients who are not getting the schedules yet in certain HD units. These number is not showing the complete data in Indonesia but it may represent the current conditions.

Several studies have calculated the quality of life of patients with HD renal replacement therapy and compared to the quality of life between ESRD patients undergo HD and CAPD therapies. Therefore, it is very important to ascertain the effects of kidney replacement therapy such as care satisfaction, quality of life, and symptom control. Research and literature review assessing the impact of PD therapy treatment on ESRD patients is still limited. Based on the background, it is necessary to identify and analyze the experience of ESRD patients through PD therapy, especially in Indonesia. The purpose of this review is to analyze PD therapy in ESRD patients.

\section{Method}

This study was conducted through scoping review to analyze PD therapy in ESRD patients by content analysis method.

\section{Search Strategy}

The strategy implemented in reviewing articles was PRISMA (Preferred Reporting Items for Systematic Reviews and Meta Analyzes). Literature search was organized based on a review of the results of original research or case reports both qualitative and quantitative, with limited article searches on electronic databases such as 
Pubmed, Proquest, and Google Scholar, with keywords compiled based on MeSH Database from NCBI; "End Stage Renal Disease" AND "Continuous Ambulatory Peritoneal Dialysis" OR "Peritoneal Dialysis" and "Quality of Life".

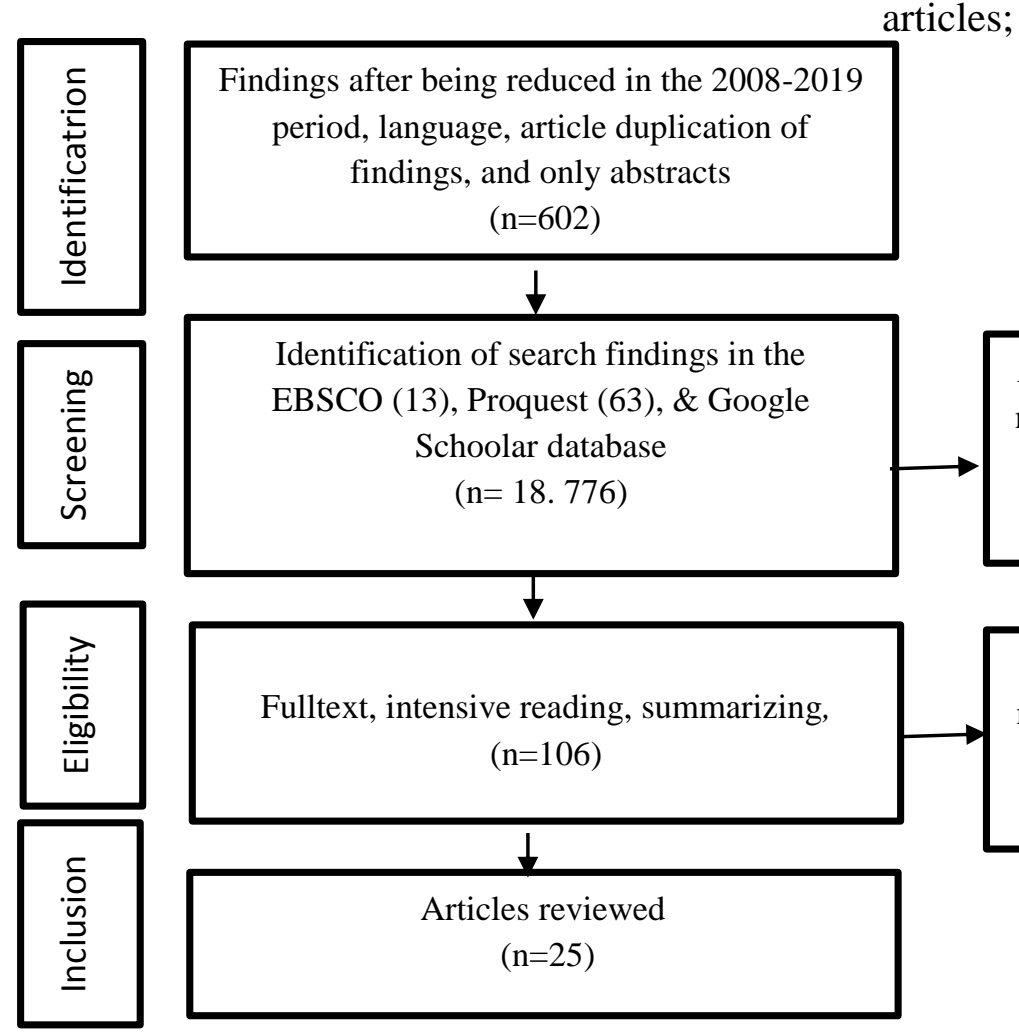

\section{Inclusion Criteria}

Qualitative and quantitative researches were reviewed by analyzing and reviewing the experiences of ESRD patients undergoing PD / CAPD therapy which aimed to determine patient satisfaction and quality of life. The process of finding specific articles on inclusion criteria such as research articles issued from 2009-2019, written in English, quantitative and qualitative designs, the subjects in kidney failure patients stage 5 with PD or CAPD therapy, open access research articles and full text. After searching and categorizing, it continued with summarizing relevant articles. Relevance consideration was based on resource clarity and correlation with the topic. The result of the analysis was in narrative.

\section{Results}

The numbers of articles discovered based on keywords were 18,776. After sorting of 20082019 publication period, language, duplicate findings, and abstracts only, it obtained 602 articles; 6 from EBSCO, 42 from Proquest, and -
Articles that are not accessible, not suit the target and inclusion

criteria

$(n=496)$

The complete text was excluded, not in line based on ESRD patients with CAPD or PD therapy $(\mathrm{n}=81)$
554 from Google Scholar. Out of 602 articles, there were 496 articles which were inaccessible, did not meet the target, and abstract only. Further reading intensively, summarizing briefly, and sorting out full-text articles were performed to 106 articles, with 81 articles excluded because it did not fit the desired population, or complications due to kidney replacement therapy undergone. Therefore, based on the inclusion criteria obtained, then the articles should be reviewed in accordance with the concept or topic were 25 articles.

\section{Summary of Article Review}

Research on the experience of ESRD patients using PD or CAPD therapy was based on evidence about treatment satisfaction and improved quality of life for ESRD patients using CAPD therapy. 
Article review was carried out on 25 articles; 15 quantitative, 7 qualitative, 2 case reports and 1 mixed method. There were 10 studies related to physical function, 8 studies stated that PD provided better physical function than HD. 9 studies discussed psychologies, 7 studies stated that HD individuals felt more anxiety and depression, and 1 study stated severe depression even leads to suicide. There were 8 studies which discussed lifestyle-related freedom with dialysis therapy selected, all studies suggested that PD provided flexibility, independence and freedom, as well as approaching to a normal life as previous before ESRD. Three studies discovered that HD patients decided to change to PD. Four studies discussed socio-economic related, and all studies suggest PD contributed social functions better than HD and 1 out of it stated that PD was more cost-effective. There were 3 studies illustrated that PD obtained better HRQoL than HD.

\section{Discussion}

Based on content analysis, in the physical domain, PD patients showed that physical function, role-physical, body pain, general health, vitality, social function, role-emotional and mental health were dominant. CAPD patients were more energetic, cheerful, and active and presented good feelings of well-being. It is due to quality of life which can change from time to time due to aging, the development of complications, changes in comorbidity and adjustment of patients to treatment (Makkar et al, 2015). The only significant difference was found was PD patients were more comfortable and pain-free than $\mathrm{HD}$ patients. Body pain has previously been found to be one of the factors which significantly contributed on the quality of life of dialysis patients (Bipath, Govender, \& Viljoen, 2014). Individuals do CAPD four times a day for 3 years, clinically these individuals have more energy, can be ambulated and have gained $10 \mathrm{~kg}$ (Moore et al, 2018). One study explained that there was a noncompliance phase in individuals with PD therapy. Patients activities were limited by doctors, but patients continued to monitor their condition for adverse consequences with laboratory results as parameters. After the patient experienced on his own, the patient would be strictly compliant, because the most common complications of PD are peritonitis and infection, which affects the morbidity and failure of PD (Lam \& Shiu, 2014), and the patient does not expect for that (Smith, 2102).

Psychological domain of PD patients, there were five studies which presented PD caused lower anxiety and depression than HD therapy which affected the quality of life of patients. It was supported by a research that PD was more dominant than $\mathrm{HD}$ in terms of perceptions of ESRD chronically disease and control abilities, such as stress, worry, or poor past medical care (Alharbia et al, 2017). In addition, dissatisfaction with health services may reflect the burden experienced by these patients, including the procedural aspects of such care as the need to travel to a dialysis center, transport problems, spend a lot of time in the medical environment and sit for long periods during dialysis ( Liles, Morris, Roskell, 2014), stress conditions during the dialysis procedure, the frequency of care spent while at the dialysis center and the long waiting times in the dialysis unit (Makkar et al, 2015; Goh \& Griva, 2018). There was one study that stated HD patients report more anxiety/insomnia, depressive symptoms and suicide (Theofilou, 2011), however, it could be an input for further research related to depression symptoms and suicidal ideation in patients with HD therapy.

Based on the content analysis, it obtained in the physical domain, patients with PD related to the physical domain found that physical function, role-physical, body pain, general health, vitality, social function, role-emotional and mental health were superior. CAPD patients were more energetic, cheerful, and active and had good feelings of well-being. Because quality of life could change from time to time due to aging, the development of complications, changes in comorbidity and adjustment of patients to treatment (Makkar et al, 2015). The only significant difference was found for body aches where PD patients were more comfortable and pain-free than HD patients. Body pain had previously been found to be one of the factors that 
had a significant impact on the quality of life of dialysis patients (Bipath, Govender, \& Viljoen, 2014). Individuals do CAPD four times a day for 3 years, clinically these individuals have more energy, can be ambulated and have gained $10 \mathrm{~kg}$ (Moore et al, 2018). One study explained that there was a phase of non-compliance in individuals with PD therapy. Patients' activities were limited by doctors, but patients continued to monitor their condition for adverse consequences with laboratory results as parameters. After the patient experiences on his own, the patient would be strictly compliant, because the most common complications of PD included peritonitis and infection which affected the morbidity and failure of PD (Lam \& Shiu, 2014), and the patient did not expect to that (Smith, 2102).

Psychological domain in PD patients showed that there were five studies which revealed PD therapy caused lower anxiety and depression than HD therapy which affected the quality of life of patients. It was supported by research that PD was dominant than HD in terms of perceptions of chronic ESRD diseases and control abilities, such as stress, anxious, or inappropriate past medical care (Alharbia et al, 2017). Furthermore, health care disappointment might reflect the burden experienced by the patients, including the procedural aspects of care as to get dialysis service, transport problems, duration in medical environment and sit for long periods during dialysis (Liles, Morris, Roskell, 2014), stress condition during dialysis, the frequency of care spent at the dialysis center and the long queue in dialysis unit (Makkar et al, 2015; Goh \& Griva, 2018). There is one study which states HD patients reports more anxiety/insomnia, depressive symptoms and suicide (Theofilou, 2011), however, it can be a trigger for further research related to depression symptoms and suicidal ideation in patients with HD therapy.

The domain of social relations in PD patients was more dominant in life aspects such as financial well-being, having flexibility to travel, diet, and dialysis access (Makkar et al, 2015). PD allows individuals to adjust their lifestyles and sets them to maintain their normal life as their past (Airheart, 2016; Lúcia et al, 2012). Besides, PD therapy can achieve and maintain normality by maximizing the flexibility, freedom, and mobility (Curtin \& Schatell, 2016). To be normal is to be ordinary, in the sense that most patients do not want their illnesses to separate them from the world they have been living with, or they have the desire to come back to their pre-dialysis life. The choice of treatment is based on the effect of the therapy to minimize disruption to its activities, to fulfill responsibilities, and to maintain personal interests, for example the ability to continue working, maintaining social life, or caring for their grandchildren (Morton et al, 2006).

Environmental domain of PD patients was more likely to continue their work so that they were financially better and free to travel than HD patients, continuing income can significantly contribute to the psychological well-being of CAPD patients. CAPD treatment offers increased autonomy and control, flexibility in daily life and fewer social limitations which can also be the reasons for better psychological health for patients (Makkar et al, 2015). Patients with terminal renal failure thought that it was not yet the time for them to die and they used their time to re-evaluate their lives; setting new priorities, such as relationships with family and friends; and reconsidered life for worship (Morton et al, 2006). Therefore, individuals decided to switch modality therapy hoping that changing their lives. After the transition from hemodialysis to PD at home, patients experienced a variety of positive benefits which result and improved quality of life (Airheart, 2016). So according to Rygh et al (2012), there would be many patients doing home dialysis in the future, so they could use telemedicine as communication, training, health control and self-management. There were systems available which made it possible to find out dialysis, blood pressure, and weight data to hospital staff and facilitate access to health facilities for those living in remote areas. Telemedicine for CAPD patients was also very likely to be investigated because of the limited research conducted related to CAPD.

One study stated a more cost effective PD modality therapy for ESRD patients. These finding was similar to other studies that CAPD 
therapy was more cost effective and optimal compared to HD and PPE in patients with ESRD in Singapore (Yang et al, 2015). However, the search for this article was limited to sources of funding or cost-benefit as well as satisfaction about care givers and patients. Further research was necessary to evaluate the cost-effectiveness of ESRD patients with CAPD therapy compared to other modality therapies to provide evidence and reinforcement and make a great impact on health policy makers in Indonesia when developing a CAPD program nationally. However, PD was less favorable since they concern about the tenckhoff catheter and the patient's ability to maintain sterility in the home environment and store dialysis supplies. (Tong et al, 2013).

As a developing country, the Indonesian government provide equitable access and facilities to dialysis in a large and broad population which is spread over more than one large archipelago. Taking into account ESRD patients who needed long-term, even lifetime dialysis, so that modality therapy was not only require a large expense in health care but it could also increase morbidity and reduced patient quality of life. Thus, CAPD therapy could be considered to reduce the long waiting time and improve the quality of life for ESRD patients.

\section{Conclusions}

A person quality of life will decrease after kidney failure. This reduction with end-stage renal failure is affected by many factors including the choice of therapeutic modality chosen by the patient. Switching modality therapy to ESRD patients from HD to PD effectively restore a patient's normal life as before experiencing ESRD and improve quality of life. Patients with PD/CAPD tend to have a better quality of life. Patients with CAPD are better in several aspects such as physical function, social function, social relations function, and relationship with the environment. Primary research should focus on the ability of a therapeutic modality/treatment by adjusting available resources to improve the quality of life of patients in developing countries such as Indonesia, because research on peritoneal dialysis especially CAPD in Indonesia is still limited. Further research can be directed towards effective and better treatments that can be facilitated by health services such as telemedicine, cost-effectiveness of CAPD therapy, life experiences of patients with CAPD as well as symptoms of depression and suicide risk in HD patients.

\section{Acknowledgments}

We thank our colleagues from lecturer, especially critical department Padjadjaran University who provided insight and expertise that greatly assisted the study, although they may not agree with all of the interpretations/ conclusions of this paper.

\section{Author Contributions}

The main authors search for articles that suitable for the topic, then analyzed. The second and third authors have reviewed and provided suggestions in the development of the article.

\section{Conflict of Interests}

There are no conflicts of interest in this study.

\section{References}

Aguiar, F., Dalosso, I. F., Bucaneve, J., Maria, N., Valerio, P., Okamoto, C. T., \& Elias, S. G. (2015). Quality of life in chronic renal patients on hemodialysis or Peritoneal Dialysis, 467-474. https://doi.org/10.5935/ $\underline{0101-2800.20150074}$

Airheart, J. W. (2016). Lived Experiences of Individuals with End-Stage Renal Disease on Peritoneal Dialysis.

Alharbia, A. A., Alraddadib, R. M., Alharbic, A. A., \& Alharbi, Y. A. (2017). Comparison of Saudi Arabian hemodialysis and peritoneal dialysis patients' illness perceptions. Renal Failure; Vol. 39, No. 1, 187-192 http://dx.doi.org/10.1080/0886022 X.2016.1256314

Arora, P. (2015). Chronic kidney disease. Diakses dari http://emedicine.medscape.com/ article /238798 overview diakses pada 19 September 2019.

Bipath, P., Govender, C., \& Viljoen, M. (2014). Journal of Psychology in Africa A Comparison of Quality of Life 
in Haemodialysis and Peritoneal Dialysis Patients A Comparison of Quality of Life in Haemodialysis and, (October), 37-41. https://doi.org/10.1080/14330237. 2008.10820243

Campbell, D., \& Craig, J. C. (2013). The Perspectives of Adults Living With Peritoneal Dialysis: YAJKD, 61(6), 873888. $\quad$ https://doi.org/10.1053/j.ajkd. $\underline{2012.08 .045}$

Chanouzas, D., Fallouh, B. et al. (2012). What influences patient choice of treatment modality at the pre-dialysis stage? Nephrology Dialysis, Transplantation 27(4), 1542-1547.

Chiang, P., Hou, J., Jong, I., Hung, P., Hsiao, C., Ma, T., \& Hsu, Y. (2016). Factors Associated with the Choice of Peritoneal Dialysis in Patients with End-Stage Renal Disease; BioMed Research International. http://dx.doi.org/10.1155/2016/5314719

Cukor, D., Cohen, S. D., Peterson, R. A., Kimmel, P. L. (2007). Psychosocial aspects of chronic disease: ESRD as a paradigmatic illness. J Am Soc Nephrol;18(12):3042-3055

Curtin, R. B., \& Schatell, D. (2016). The Peritoneal Dialysis Experience: Insights from Long-Term Patients, Nephrology Nursing Journal, vol. 31, no. 6 .

Dimkovic, N., Oreopoulos, D. G. (2008). Assisted peritoneal dialysis as a method of choice for elderly with end-stage renal disease. Int Urol Nephrol;40(4):1143-50

Fundacion Mexiana del Rinon. (2007). Fundación Mexicana del Riñón, 2007. Diakses dari http://www.fundrenal.org.mx/

Gaipov, A. (2012). Sleep quality , depression , and quality of life in elderly hemodialysis patients, International Journal of Nephrology and Renovascular Disease;5 $135-142$

Ginieri-Coccossis, M., Theofilou, P., Synodinou, C. et al. (2008). Quality of life, mental health and health beliefs in haemodialysis and peri- toneal dialysis patients: investigating differences in early and later years of current treatment. BMC Nephrology 9, 14

Goh, Z., S., \& Griva, K. (2018). Anxiety and depression in patients with end-stage renal disease: impact and management challenges - a narrative review, International Journal of Nephrology and Renovascular Disease 2018:11 93-102.
Gonçalves, F. A., Dalosso, I. F., Borba, J. M. C., Bucaneve, J., Valerio, N. M. P., Okamoto, C. T., Bucharles, S. G. E. (2015). Quality of life in chronic renal patients on hemodialysis or peritoneal dialysis: a comparative study in a referral service of Curitiba - PR. J Bras Nefrol;37(4):467-474.https://doi.org/10.5935/ 0101$\underline{2800.20150074}$

Guo, A. \& Mujais, S. (2003). Patient and technique survival on peritoneal dial- ysis in the United States: Evaluation in large incident cohorts. Kidney International, 64(suppl 88), S3-S12.

Heaf, J. (2004). Underutilization of peri- toneal dialysis. Journal of the American Medical Association, 291(6), $740-742$

Helantera, I., Haapio, M., Koskinen, P. et al. (2012). Employment of patients receiving maintenance dialysis and after kidney transplant: a cross-sectional study from Finland. American Journal of Kidney Diseases 59(5), 700-706

Hope, J., \& Stortford, B. (2013). A patient perspective on the barriers to home dialysis, Journal of Renal Care 39(Suppl. 1), 3-8 39, 3-8.

Jassal, S. V., Trpeski, L., Zhu, N., Fenton, S., Hemmelgarn, B. (2007). Changes in survival among elderly patients initiating dialysis from 1990 to 1999. CMAJ.;177(9):1033-8

Jiao, Y., Gao, S., Wu, L., \& Song, A. (2017). Continuity of care for quality of life and clinical outcomes in patients with peritoneal dialysis, 10(12), 16586-16594.

Jung, H., Jeon, Y., Park, Y., Kim, Y. S., Kang, S., Yang, C. W., Park, S. (2019). Better Quality of Life of Peritoneal Dialysis compared to Hemodialysis over a Two-year Period after Dialysis Initiation. Scientific Reports, (July), 1-10. https://doi.org/10.1038/s41598-01946744-1

Just, P. M., Riella, M. C., Tschosik, E. A. et al. (2008). Economic evaluations of dialysis treatment modalities. Health Policy 86(2/3), 163-180

Korevaar, J.C., Feith, G.W., Dekker, F.W., Van Manen, J.G., Boeschoten, E.W., Bossuyt, P.M., \& Krediet, R.T.: NECOSAD Study Group. (2003). Effect of starting with hemodialysis compared with peritoneal dialysis in patients new on dialysis treatment: A randomized controlled trial. Kidney International, 64(6), 2222-2228.

Lam, L. W., Lee, D. T. F., \& Shiu, A. T. Y. (2014). International Journal of Nursing Studies The dynamic 
process of adherence to a renal therapeutic regimen: Perspectives of patients undergoing continuous ambulatory peritoneal dialysis. International Journal of Nursing Studies, 51(6), 908-916. https://doi.org/10.1016/j.ijnurstu.2013.10.012

Liles, C., Morris, A., Roskell, C. (2014). Exploring the challanges of living with peritoneal dialysis. Journal of renal nursing, vol. 7 no. 4

Lúcia, M., Sadala, A., Azevedo, G., Bruzos, D. S., Pereira, E. R., \& Bucuvic, E. M. (2012). Patients' experiences of peritoneal dialysis at home: a phenomenological approach, 20(1), 68-75.

Luo, F. Y. N., Yu, T. L. Z. L., \& Griva, M. W. Y. F. K. (2018). Health-Related Quality of Life in Patients Treated with Continuous Ambulatory Peritoneal Dialysis and Automated Peritoneal Dialysis in Singapore, 203-208. https://doi.org/10.1007/s41669017-0046-Z

Makkar, V., Kumar, M., Mahajan, R., \& Khaira, N. S. (2015). Comparison of Outcomes and Quality of Life between Hemodialysis and Peritoneal Dialysis Patients in Indian ESRD Population, 28-32. https://doi.org/10.7860/JCDR/2015/11472.5709

Martin-mcdonald, K., \& Queensland, S. (2003). Being dialysis-dependent: A qualitative perspective, Collegian 10(2), 29-33.

Masytoh, L. S., \& Nadjib, M. (2019). Quality of Life Measurement of End-Stage-Renal Disease Patients in Indonesia based on responses to the EQ-5D-3L questionnaire. Journal of International Dental and Medical Research; (1) vol. 12 331-337.

Moore, J., Garcia, P., Rohloff, P., \& Flood, D. (2018). Treatment of end-stage renal disease with continuous ambulatory peritoneal dialysis in rural Guatemala, BMJ Case, 1-5. https://doi.org/10.1136 /bcr-2017$\underline{223641}$

Morton, R. L., Tong, A., Howard, K., Snelling, P., Webster, A. C. (2006). The views of patients and carers in treatment decision, BMJ, 340:c112 1-10. https://doi.org/10.1136/bmj.c112

Novelia, E., Nugraha, R. R., \& Thabrany, H. (2015). Cost effectiveness analysis between hemodialysis and peritoneal dialysis. Jurnal Ekonomi Kesehatan Indonesia; Volume 1, Nomor 3.

Okaka, E. I., Naidoo, S., Ahmed, M. M., Davies, M., \& Naicker, S. (2015). Quality of Life in Patients on Continuous Ambulatory Peritoneal Dialysis in an
African Setting, Saudi J Kidney Dis Transpl;26(3), 631-637.

Rubin, H. R., Fink, N. E., Plantinga, L. C., Sadler, J. H., Kliger, A. S., \& Powe, N. R. (2004). Patient ratings of dialysis care with peritoneal vs. hemodial- ysis. Journal of the American Medical Association, 291(6), 697-703

Rygh, E., Arild, E., Johnsen, E., \& Rumpsfeld, M. (2012). Choosing to live with home dialysis-patients' experiences and potential for telemedicine support: a qualitative study. BMC Nephrology 2012, 13:13

Smith, A. (2012). End-stage renal disease and renal replacement therapy in older patients. Nephro-Urology Monthly, 4(2), 425-430. https://doi.org/10.5812/numonthly.1825

Stel, V. S., Kramer, A., Zoccali, C., Jager, K. J. (2009). The 2006 ERA-EDTA Registry annual report: a precis. J Nephrol;22(1):1-12

Tannor, E. K., Archer, E., Kapembwa, K., Schalkwyk, S. C. Van, \& Davids, M. R. (2017). Quality of life in patients on chronic dialysis in South Africa: a comparative mixed methods study, 1-10. https://doi.org/10.1186/s12882-016-0425-1

Theofilou, P. (2011). Quality of Life in Patients Undergoing Hemodialysis or Peritoneal Dialysis Treatment, 3(3), 132-138. https://doi.org/10.4021/ jocmr552w

Tong, A., Lesmana, B., Johnson, D. W., Wong, G., Campbell, D., \& Craig, J. C. (2013). The Perspectives of Adults Living With Peritoneal Dialysis: YAJKD, 61(6), 873-888. https://doi.org/10.1053/j.ajkd.2012.08.045

Turkmen, K., Guney, I., Yazici, R., Arslan, S., Altintepe, L., \& Yeksan, M. (2014). Health-related quality of life, depression and mortality in peritoneal dialysis patients in Turkey : seven-year experience of a center, 6049(6), 859-864.

https://doi.org/10.3109/ 0886022X.2014.899874

U.S. Renal Data System (USRDS). (2003). USRDS 2003 annual data report: Atlas of end-stage renal disease in the United States. Bethesda, MD: National Institutes of Health, National Institute of Diabetes and Digestive and Kidney Diseases, 78-80.

UK Renal Registry. (2011). Fig. 2.6. Chapter 2. Treatment modality in prevalent RRT patients on 31/12/2010. http://www.renalreg. com/index.html pada 19 September 2019. 
Wong, B., Ravani, P., Oliver, M. J., Holroyd-leduc, J., Venturato, L., Garg, A. X., \& Quinn, R. R. (2018). Comparison of Patient Survival Between Hemodialysis and Peritoneal Dialysis Among Patients Eligible for Both\&nbsp;Modalities. American Journal of Kidney Diseases, 71(3), 344-351. https://doi.org/10.1053/j.ajkd. 2017.08.028

Yang, F., Lau, T., \& Luo, N. (2015). Cost-effectiveness of haemodialysis and peritoneal dialysis for patients with end-stage renal disease in Singapore. doi: 10.1111/nep.126 